\title{
Surface free energy and dynamic wettability of wood simultaneously treated with acidic dye and flame retardant
}

\author{
Xiaoqian Wang ${ }^{1}$ Fang Wang ${ }^{1}$ Zhiming $\mathrm{Yu}^{1} \cdot$ Yang Zhang ${ }^{1} \cdot$ Chusheng $\mathrm{Qi}^{1}$ • \\ Lanxing $\mathrm{Du}^{1}$
}

Received: 18 November 2016 / Accepted: 17 February 2017 / Published online: 27 March 2017

(C) The Japan Wood Research Society 2017

\begin{abstract}
The use of multifunctional wood for decorative purpose has grown increasingly popular in recent years. In this study, fast-growing poplar wood was treated with dye $(0.5 \%)$ and flame retardant $(0,10,20$, and $30 \%)$ simultaneously to enhance its visual characteristic and safety. The dynamic wettability and surface free energy of wood samples were studied using S-D wetting model and van Oss-Chaudhury-Good (vOCG) method, respectively. Dye uptake, drug load, color difference, and combustion performance were determined. The treated wood was also characterized by infrared spectroscopy, scanning electron microscopy, and energy-dispersive X-ray spectroscopy. The results indicated that the proposed treatment yields favorable adhesive spreading and penetration ability at the wood surface. The surface free energy of treated wood was higher than that of untreated wood, and the dye uptake, drug load, color difference, and limited oxygen index all increased after the proposed combination treatment compared to dyeonly treated wood. The results also indicated that the flame retardant reacted chemically with the wood as the dye and flame retardant molecules diffused into the cell cavity, wood vessel, and aperture.
\end{abstract}

Keywords Surface free energy - Dynamic wettability . Color difference $\cdot$ Flame-retardant performance

Zhiming Yu

yuzhiming@bjfu.edu.cn

Yang Zhang

bjfuzhangyang@bjfu.edu.cn

1 MOE Key Laboratory of Wooden Material Science and Application, Beijing Forestry University, P. O. Box 734, Qinghua East Road 35, Beijing 100083, China

\section{Introduction}

Wood is a porous material mainly composed of cellulose, hemicelluloses, and lignin, as well as extractives [1]. It is commonly used in combination with other materials such as adhesives, dyes, and flame retardants. The wetting behavior and surface free energy between wood and any of these other materials are crucial in terms of predicting the performance of the wood-polymer systems [2].

Fast-growing poplar wood, a common species in Northern China, is widely used as an alternative for precious woods due to its loose fiber structure, lower density, and good permeability. Despite several advantageous qualities, the poplar's superficial color is relatively bland and variations in tone reduce its aesthetic value $[3,4]$. Wood dyeing eliminates color differences and improves the visual characteristics of wood products; more importantly, dyeing wood like fast-growing poplar wood can make them appear similar to higher valued wood species. Another disadvantageous property of wood (especially the fast-growing woods) is its flammability which restricts its application in furniture, decoration, and construction industries [5-8]. Flame-retardancy treatment is a crucial precautionary measure for wood materials [9]. Thus, the fast-growing poplar wood was simultaneously treated with acidic dye and flame retardant which can improve the aesthetic aspects and safety. More importantly, the treated wood surface characteristics, wettability, and surface free energy play a vital role in wood based panel processing.

"Wettability" refers to the process through which a liquid spreads over a solid surface [10]. The wettability of a given wood surface, one of the preconditions for bonding behavior, is an important parameter that describes the behavior of a liquid (e.g., water, coating, and adhesive) in contact with the wood surface $[11,12]$. It plays an important role in 
the ability of adhesives to wet, flow, penetrate, and cure on wood surfaces [13]. Sufficient wetting of the wood surface by aqueous resin solutions can generate a strong adhesive joint [14]. Wood surface wettability is typically measured via contact angle. The smaller the contact angle, the better the surface wettability. Most woods reach excellent wettability at a contact angle less than or equal to $30^{\circ}$ [15].

The surface free energy of a solid also affects its wettability. A solid with high surface free energy is more easily wetted than one with low surface free energy [16]. The surface free energy of wood, specifically, is often correlated with the biological interactions between the wood surface and other materials [17]. To some extent, the greater the surface free energy, the better the spreadability of a liquid on the wood surface [18]. It also has an important influence on the bonding strength of wood composites [19]. The surface free energy of wood can, similar to its wettability, be determined according to the contact angle of reference liquids on the wood surface.

Until now, a few studies have focused on the treated wood with dye and flame retardant. Zhang studied Populus tomentosa veneer which was treated with dye and flame retardant, and then hot-pressed into laminated veneer lumber (LVL) whose physical and mechanical properties were tested [20]. Li prepared a wood veneer, processed with direct dyes, reactive dyes, acid dyes, and flame retardant, from which a multifunctional plywood was produced [21]. They paid attention to the natural properties of plywood or LVL, while a little research has been concerned with the wood veneer surface characteristics. Furthermore, studies on wood treated with combined dye and flame retardant have not been sufficiently comprehensive.

The primary goal of this study was to investigate the dynamic wettability and surface free energy of wood simultaneously treated with dye and flame retardant. We also explored the effects of BL-flame retardant concentration on dye uptake, drug load, color parameters, and limited oxygen index. Fourier transform infrared spectroscopy (FTIR) was utilized to determine the combined mechanism of dye or flame retardant with wood. Scanning electron microscopy (SEM) and energy-dispersive X-ray spectroscopy (EDX) were utilized to observe the distribution of dye and flame-retardant molecules within the wood veneer.

\section{Materials and methods}

\section{Materials}

Fast-growing poplar wood ( $P$. tomentosa Carr.) and phenol-formaldehyde (PF) resin adhesive were supplied by Kaiyuan Wood Factory in Harbin, China. The poplar wood veneer sample dimensions were $100 \mathrm{~mm} \times 100 \mathrm{~mm} \times 1.0 \mathrm{~mm}$ (length $\times$ width $\times$ thickness). The veneers were air-dried to $10-12 \%$ moisture content. Acid red GR (C.I. Acid Red 73) was provided by Taopu Dye Plant in Shanghai, China. BL-flame retardant, nitrogen-phosphorus (N-P) flame-retardant type, was obtained from the College of Materials Science and Technology at Beijing Forestry University, China. Formamide and diiodomenthane (HPLC grade) were purchased from Tianjin Chemistry Company. Distilled water was used for the preparation of all solutions. The molecular structures of BLflame retardant and acid red GR are shown in Fig. 1.

\section{Dyeing and flame-retardancy treatment}

A dip-dye method at atmospheric pressure was used for wood veneer dyeing and flame-retardancy treatment. Acid red GR dye $(0.5 \%)$ and BL-flame retardant $(0,10,20$, and $30 \%$ ) were dissolved into distilled water, and then, the sample veneers were vertically immersed in the solution with sufficient space between each other. All of the experimental groups were heated at a temperature of $60^{\circ} \mathrm{C}$ and a dipping time of $180 \mathrm{~min}$ in an electro thermostatic water bath. A bath ratio of 1:20 ( $\left.V_{\text {veneer }}: V_{\text {solution }}\right)$ was maintained throughout the experiment. The solution was stirred clockwise every $15 \mathrm{~min}$ to ensure even penetration. After dyeing and flameretardancy treatment, the treated wood samples were rinsed thoroughly with distilled water to wash away any residual dye

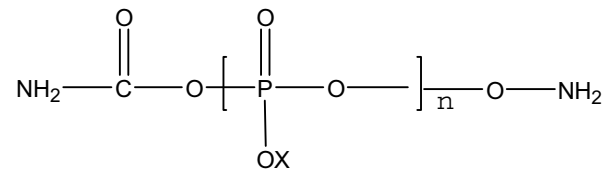

(a)



(b)

Fig. 1 Chemical structure of main BL-flame-retardant components (a), where $\mathrm{X}$ represents $\mathrm{H}, \mathrm{NH}_{4}$, or $\mathrm{CO}-\mathrm{NH}_{2}$ and chemical structure of acid red GR (b) 
or flame retardant from the wood surface. The samples were then air-dried to $10-12 \%$ moisture content in a cool and dark environment.

\section{Characterization}

\section{Fourier transform infrared spectroscopy (FTIR) characterization}

FTIR was used to characterize the chemical structure of the treated and untreated wood samples. The samples were milled to 200-mesh size and mixed with potassium bromide pellets prior to FTIR spectrophotometry (Nicolet 6700 Thermo Scientific, USA) in the range of 4000-400 and at $4 \mathrm{~cm}^{-1}$ resolution for 32 scans.

\section{Measurement of dye uptake and drug load}

Dye uptake was characterized by dye absorption from the dye bath to the veneer sample. A UV-Visible spectroscopy (721 ApL, China) at $\lambda_{\max } 510 \mathrm{~nm}$ was utilized to determine the absorption. Dye uptake was calculated according to the following equation [22]:

$E \%=\frac{C_{\mathrm{O}}-C_{\mathrm{f}}}{C_{\mathrm{O}}} \times 100 \%$,

where $C_{\mathrm{O}}$ and $C_{\mathrm{f}}$ are the concentration of the dye solution before and after dyeing, respectively.

The drug loads (the amount of BL-flame retardant in the treated samples) were calculated as follows [23]:

$y=\frac{M_{1}\left(1-U_{1}\right)-\left(m_{1}-m_{0}\right)-M_{0}\left(1-U_{0}\right)}{V}$,

where $y$ is the drug load $\left(\mathrm{kg} / \mathrm{m}^{3}\right), M_{1}$ is the specimen mass after treatment $(\mathrm{kg}), U_{1}$ is the moisture content of the wood specimen after treatment (\%), $m_{1}$ is the dye mass before treatment $(\mathrm{kg}), m_{0}$ is the dye mass after treatment $(\mathrm{kg}), M_{0}$ is the specimen mass before treatment $(\mathrm{kg}), U_{0}$ is the moisture content of the wood specimen before treatment (\%), and $V$ is the specimen volume before treatment $\left(\mathrm{m}^{3}\right)$.

\section{Color parametes measurements}

The surface color difference of sample veneers was evaluated based on the CIELAB color coordinates. A color measuring instrument (Dataflash 110 Datacolor, USA) was utilized to record the color index with illuminant D65 and a $10^{\circ}$ standard observer. The color parameters of each specimen were measured at six positions and the mean value was recorded. The total color difference $\left(\Delta E^{*}\right)$ was used to assess the dyeing effect of veneers. $\Delta E^{*}$ was calculated as follows [24]:

$\Delta L^{*}=L_{1}^{*}-L_{0}^{*}$
$\Delta a^{*}=a_{1}^{*}-a_{0}^{*}$

$\Delta b^{*}=b_{1}^{*}-b_{0}^{*}$

$\Delta E^{*}=\left(\Delta L^{* 2}+\Delta a^{* 2}+\Delta b^{* 2}\right)^{1 / 2}$,

where $\Delta E^{*}$ represents the total color difference, $L^{*}$ is the lightness and darkness of color, $a^{*}$ is the redness and greenness of color, $b^{*}$ denotes the yellowness and blueness of color, and $\Delta L^{*}, \Delta a^{*}$, and $\Delta b^{*}$ are the differences of the wood sample values before and after treatment of $L^{*}, a^{*}$, and $b^{*}$, respectively.

\section{Limited oxygen index measurements}

The flame retardancy of the samples was evaluated according to limited oxygen index (LOI) measurements. LOI is the minimum amount of oxygen in an oxygen-nitrogen mixture required to support the complete combustion of a vertically held sample burning from the top down; the higher the LOI value, more effective the flame retardant. We measure LOI values in accordance with ISO 4589-2:1996 standards as recorded by an automatic oxygen index instrument (LFY605, China) [25]. The samples subjected to LOI tests were $100 \mathrm{~mm} \times 10 \pm 0.5 \mathrm{~mm} \times 1 \mathrm{~mm}$ (length $\times$ width $\times$ thickness). Fifteen specimens were prepared for each group. The experimental device was placed at $23 \pm 2{ }^{\circ} \mathrm{C}$ and the initial oxygen concentration was $21 \%$ (volume fraction). Samples were placed vertically and in the center of the combustion cylinder, and then, $\mathrm{O}_{2} / \mathrm{N}_{2}$ was mixed at $23 \pm 2{ }^{\circ} \mathrm{C}$ until reaching a predetermined value and top surface ignition was applied. LOI was calculated as follows:

$\mathrm{LOI}=100 \frac{V_{\mathrm{O}}}{V_{\mathrm{O}}+V_{\mathrm{N}}}$,

where $V_{\mathrm{O}}$ is the oxygen volume of per unit volume of mixed gas at $23^{\circ} \mathrm{C}$, and $V_{\mathrm{N}}$ is the nitrogen per unit volume of mixed gas at $23^{\circ} \mathrm{C}$.

Scanning electron microscopy (SEM) and energy-dispersive $X$-ray spectroscopy (EDX) studies

SEM (Hitachi S-3400N, Japan) was applied at an accelerating voltage of $15 \mathrm{kV}$ to observe the morphology of treated wood veneer samples. The tangential sections of untreated and treated wood samples were fixed on conductive adhesives and coated with gold prior to analysis. The samples were also subjected to energy-dispersive $\mathrm{X}$-ray analysis (EDX) to determine the quantities of characteristic elements. 


\section{Contact angle measurements}

The wetting behavior of treated wood samples was determined with a contact angle instrument (OCA 20 DataPhysics Instruments GmbH, Filderstadt, Germany) equipped with a video measuring system, high-resolution CCD camera, and high-performance digitizing adapter that enables instantaneous and frequent registration. SCA 20 software (DataPhysics Istruments GmbH, Filderstadt, Germany) was utilized for data collection. Two polar liquids (water and formamide) and one non-polar liquid (diiodomenthane) were used. A $3 \mu \mathrm{L}$ drop of test liquid was placed on the wood samples surface for each measurement. Three test drops of each sample were performed for all three liquids and PF adhesives, and four wood samples were used per liquid to avoid non-homogeneity. The right and left contact angles between each droplet and the sample surface were collected at intervals of $1 \mathrm{~s}$ during the first $10 \mathrm{~s}$ and intervals of $10 \mathrm{~s}$ for a total duration of $80 \mathrm{~s}$, and then, the average of the contact angles was automatically calculated to determine the surface free energy.

\section{Surface free energy measurements}

The surface free energy of wood is typically calculated based on the Young equation, $\gamma_{S}=\gamma_{L} \cos \theta+\gamma_{S L}$, where $\gamma_{S}$ is the surface tension of the solid, $\gamma_{\mathrm{L}}$ is the surface tension of the liquid, $\gamma_{\mathrm{SL}}$ is the surface tension of the solid-liquid interface, and $\theta$ is the contact angle between the solid and liquid.

The acid-base theory developed by van Oss, Chaudhury, and Good (i.e., the vOCG method), under which surface tension components are closely related to their chemical nature [26], has garnered considerable research interest in recent years. Per vOCG, the surface free energy is expressed as follows:

$\gamma_{S}=\gamma_{\mathrm{S}}^{\mathrm{LW}}+\gamma_{\mathrm{S}}^{\mathrm{AB}}=\gamma_{\mathrm{S}}^{\mathrm{LW}}+2\left(\gamma_{\mathrm{S}}^{-} \gamma_{\mathrm{S}}^{+}\right)^{1 / 2}$.

Combining Eq. (8) with Yong's equation yields:

$\gamma_{\mathrm{L}}(1+\cos \theta)=2\left(\gamma_{\mathrm{S}}^{\mathrm{LW}} \gamma_{\mathrm{L}}^{\mathrm{LW}}\right)^{\frac{1}{2}}+2\left(\gamma_{\mathrm{S}}^{+} \gamma_{\mathrm{L}}^{-}\right)^{\frac{1}{2}}+2\left(\gamma_{\mathrm{S}}^{-} \gamma_{\mathrm{L}}^{+}\right)^{\frac{1}{2}}$,

where $\gamma_{\mathrm{S}}$ is the surface free energy of solids, $\gamma_{\mathrm{S}}^{\mathrm{LW}}$ is the Lifshitz-van der Waals-based surface free energy for solids, $\gamma_{\mathrm{S}}^{\mathrm{AB}}$ is the acid-base-based surface free energy for solids, $\gamma_{\mathrm{S}}^{+}$is the acid-based surface free energy for solids, $\gamma_{\mathrm{S}}^{-}$is the base-based surface free energy for solids, $\gamma_{\mathrm{L}}$ is the surface free energy for liquids, $\gamma_{\mathrm{L}}^{\mathrm{LW}}$ is the Lifshitz-van der Waalsbased surface free energy for liquids, $\gamma_{\mathrm{L}}^{\mathrm{AB}}$ is the acid-basebased surface free energy for liquids, $\gamma_{\mathrm{L}}^{+}$is the acid-based surface free energy for liquids, $\gamma_{\mathrm{L}}^{-}$is the base-based surface free energy for liquids, and $\theta$ is the tested contact angle.
In this study, distilled water, formamide, and diiodomenthane with known energy characteristics were used to calculate the surface free energy of treated wood samples (Table 1) [27].

Dynamic wettability of adhesives on treated wood veneer surfaces

In our experiments, the measured contact angles formed once adhesive drops were placed on the wood veneer surface, and then decayed as time progressed due to the porosity and anisotropy of wood. Several wetting models have been proposed to describe this dynamic wetting process [28-31], among which the S-D model is most widely used. It is expressed as follows [32]:

$\theta=\frac{\theta_{\mathrm{i}} \cdot \theta_{\mathrm{e}}}{\theta_{\mathrm{i}}+\left(\theta_{\mathrm{e}}-\theta_{\mathrm{i}}\right) \exp \left[K\left(\theta_{\mathrm{e}} /\left(\theta_{\mathrm{e}}-\theta_{\mathrm{i}}\right)\right) t\right]}$,

where $\theta_{\mathrm{i}}$ is the initial (instantaneous) contact angle, $\theta_{\mathrm{e}}$ is the equilibrium contact angle, $\theta$ is the contact angle at a certain time, $t$ represents the wetting time, and $K$ is a constant referring to the intrinsic relative contact angle decrease rate. The physical meaning of the $K$ value represents how fast the liquid spreads and penetrates into the porous structure of a wood sample. The higher the $K$ value, the faster the rate of adhesive penetration and spreading. We obtained the $K$ values of the adhesive and treated wood veneer system via a nonlinear curve-fitting method.

\section{Statistical analysis}

Experiments were performed in either three or four replicates. The obtained data were analyzed with analysis of variance (ANOVA). The difference among samples was determined using Duncan's multiple-range test at $p=0.05$ [33].

Table 1 Surface tension and components of three different test liquids

\begin{tabular}{llllll}
\hline Liquid & \multicolumn{5}{l}{ Surface free energy $\left(\mathrm{mJ} / \mathrm{m}^{2}\right)$} \\
\cline { 2 - 6 } & $\gamma_{\mathrm{L}}$ & $\gamma_{\mathrm{L}}^{\mathrm{LW}}$ & $\gamma_{\mathrm{L}}^{\mathrm{AB}}$ & $\gamma_{\mathrm{L}}^{+}$ & $\gamma_{\mathrm{L}}^{-}$ \\
\hline Distilled water & 72.8 & 21.8 & 51.0 & 25.5 & 25.5 \\
Formamide & 58.0 & 39.0 & 19.0 & 2.28 & 39.6 \\
Diiodomenthane & 50.8 & 50.8 & 0 & 0 & 0 \\
\hline
\end{tabular}




\section{Results and discussion}

\section{FTIR analysis}

Figure 2 shows the FTIR spectra for untreated and treated wood veneer samples. The spectra of untreated and dyed wood samples were similar, suggesting that there was no chemical reaction between the dye and wood veneer. Conversely, the absorption peak of fire-retardant-treated wood at $2915 \mathrm{~cm}^{-1}$ (C-H stretch) declined, suggesting that the aliphatic extractives shifted and the polysaccharide in the hemicelluloses hydrolyzed [21]. The $1741 \mathrm{~cm}^{-1}$ band $(\mathrm{O}=\mathrm{C}-\mathrm{OH}$ group of the glucuronic acid unit) also decreased, reflecting the deacetylation of hemicelluloses under acidic conditions [34]. A new band at $518 \mathrm{~cm}^{-1}$ (P-O-P absorption of BL-flame retardant) indicates a polycondensation reaction between phosphoric acid and lignin [35].

\section{Dye uptake and drug load}

The dye uptake and drug load of the treated wood samples are presented in Table 2. Dye uptake markedly increased at first, and then slightly decreased as the BL-flame-retardant addition increased. The dye uptake increased from $3.82 \%$ at $0 \%$ BL-flame retardant to $16.48 \%$ at $20 \%$ BL-flame retardant. The significant increase $(p<0.01)$ in dye uptake is attributed to a reduction in the repulsive force between the dye chromophores and fiber surfaces as the flame-retardant



Fig. 2 FTIR spectra: a untreated wood, $\mathbf{b}$ dyed wood, and $\mathbf{c}$ dyed and fire-retardant-treated wood concentration increased, which produced acidic conditions [36]. When the BL-flame-retardant concentration reached $30 \%$, however, the dye uptake decreased to $13.87 \%$, counting for a significant decrease of $15.84 \%(p<0.01)$. At higher BL-flame-retardant concentration, an excess of flame-retardant molecules in the solution dominated the dye molecules and occupied cell cavities, the wood vessel, and the aperture to impede the dye molecules from penetrating the wood. Addition of BL-flame retardant promoted dye uptake which could reduce the dosage of the dyestuff and save cost for industry.

The drug load also increased as BL-flame-retardant concentration increased, reaching a maximum of $68.96 \mathrm{~kg} /$ $\mathrm{m}^{3}$ which was higher than that of the study by Zhang et al. $\left(57.7 \mathrm{~kg} / \mathrm{m}^{3}\right)$ at BL-flame-retardant concentration of $30 \%$ [23]. The higher concentration of BL-flame retardant enhanced the reactivity between flame-retardant and wood components. Furthermore, the greater number of flameretardant molecules was better able to penetrate wood samples.

\section{Color difference}

Figure 3 and Table 3 show the surface color and color differences of wood samples, respectively. The dyed wood had the highest $L^{*}$ of $54.386 \pm 0.992$ and $b^{*}$ of $38.013 \pm 1.078$, respectively. $L^{*}$ decreased significantly with increasing flame-retardant concentration $(p<0.05)$. It is due to the fact that wood extractives were extracted during the dyeing and inflaming retarding process [37]. Upon the addition of flame retardant, $b^{*}$ showed a downward trend, which might be attributed to the increasing BL-flame-retardant concentration that exacerbated the poly-condensation reaction between phosphoric acid and lignin. High level of BLflame-retardant addition (30\%) seemed to pose no effect on $b^{*}(p>0.05)$. Moreover, the increment of $a^{*}$ was insignificant $(p>0.05)$. However, the color difference significantly increased as BL-flame-retardant concentration increased $(p<0.05)$, reaching a maximum value of $18.016 \pm 1.251$ at BL-flame-retardant concentration of $30 \%$.

The dye used in this study contains the negatively charged sulfonic group $\left(\mathrm{RSO}_{3}{ }^{-}\right)$and the wood fiber is also negatively charged in the solution [38], so during dyeing, there was a repulsive force between the dye and wood fiber. It is this repulsive force that hindered the dye molecules
Table 2 Dye uptake and drug load of poplar wood veneers treated with dye and flame retardant (standard deviations in parentheses)

\begin{tabular}{lcl}
\hline Sample & Dye uptake $(\%)$ & Drug load $\left(\mathrm{kg} / \mathrm{m}^{3}\right)$ \\
\hline Dyed wood with BL-flame-retardant concentration of 0\% & $3.82( \pm 0.06)$ & - \\
Dyed wood with BL-flame-retardant concentration of 10\% & $10.41( \pm 0.04)$ & $21.15( \pm 0.03)$ \\
Dyed wood with BL-flame-retardant concentration of 20\% & $16.48( \pm 0.04)$ & $43.26( \pm 0.08)$ \\
Dyed wood with BL-flame-retardant concentration of 30\% & $13.87( \pm 0.03)$ & $68.96( \pm 0.04)$ \\
\hline
\end{tabular}



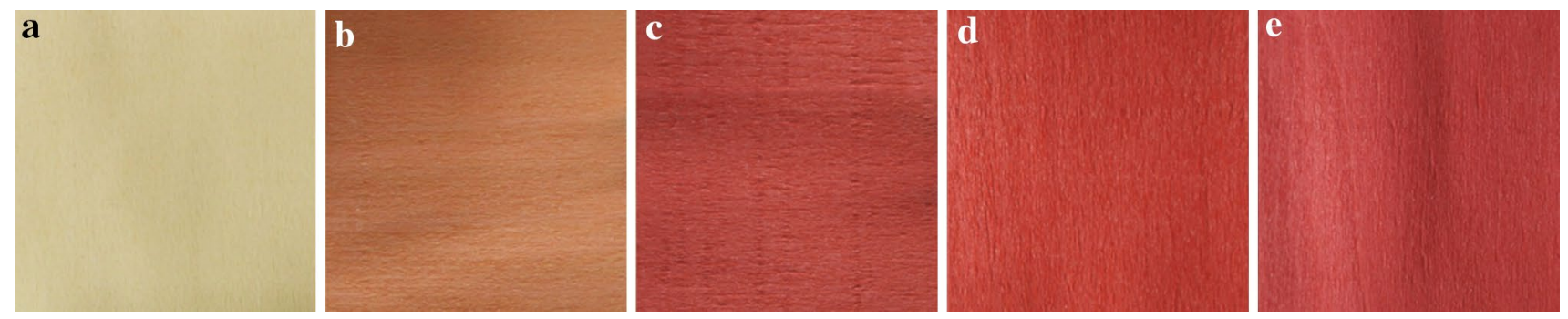

Fig. 3 Surface color of untreated and treated wood samples: a untreated wood, b dyed wood veneer with BL-flame-retardant concentration of $0 \%$, $\mathbf{c}$ dyed wood veneer with BL-flame-retardant con- centration of $10 \%, \mathbf{d}$ dyed wood veneer with BL-flame-retardant concentration of $20 \%$, and e dyed wood veneer with BL-flame-retardant concentration of $30 \%$

Table 3 Color differences of poplar wood veneers treated with dye and flame retardant

\begin{tabular}{lllll}
\hline Color parameter $^{\mathrm{a}}$ & $\begin{array}{l}\text { Dyed wood with BL-flame- } \\
\text { retardant concentration of } 0 \%\end{array}$ & $\begin{array}{l}\text { Dyed wood with BL-flame- } \\
\text { retardant concentration of } \\
10 \%\end{array}$ & $\begin{array}{l}\text { Dyed wood with BL-flame- } \\
\text { retardant concentration of } \\
20 \%\end{array}$ & $\begin{array}{l}\text { Dyed wood with BL-flame- } \\
\text { retardant concentration of } \\
30 \%\end{array}$ \\
\hline$L^{*}$ & $54.386 \pm 0.992$ & $42.036 \pm 0.624$ & $39.696 \pm 0.522$ & $37.850 \pm 0.630$ \\
$a^{*}$ & $48.461 \pm 0.850$ & $49.510 \pm 0.645$ & $48.640 \pm 0.728$ & $49.505 \pm 1.341$ \\
$b^{*}$ & $38.013 \pm 1.078$ & $33.242 \pm 0.580$ & $31.133 \pm 0.536$ & $31.053 \pm 0.772$ \\
$\Delta E^{* \mathrm{~b}}$ & - & $13.340 \pm 0.996$ & $16.258 \pm 1.256$ & $18.016 \pm 1.251$ \\
\hline
\end{tabular}

${ }^{\mathrm{a}}$ Color parameters calculated with Eqs. (3-5)

${ }^{\mathrm{b}} \Delta E^{*}$ was calculated with Eq. (6)

from absorbing and penetrating the wood samples. After adding the flame retardant, however, the solution became acidic due to the presence of phosphoric acid and was thus able to ionize $\mathrm{H}^{+}$. Furthermore, the primary component of flame retardant, ammonium polyphosphate can ionize $\mathrm{NH}_{4}{ }^{+}$[39]. The negative surface charges of the wood fiber were neutralized by $\mathrm{H}^{+}$and $\mathrm{NH}_{4}^{+}$. In addition, the $\mathrm{NH}_{4}^{+}$ can provide dye sites for $\mathrm{RSO}_{3}{ }^{-}$. To this effect, the repulsive force between dye chromophores and wood fiber surfaces was reduced, allowing more dye molecules to penetrate the wood and increasing the surface color difference of the treated wood. From the above analysis, the flame retardant could affect the wood surface color, so the color can be controlled by the additive amount of flame retardant.

\section{Limited oxygen index}

Compared to the study by $\mathrm{Li}$ et al., the LOI value improved and it showed the biggest increment $(26.24 \%)$ at $20 \%$ BLflame retardant [37]. As shown in Fig. 4, BL-flame-retardant addition was found to pose a significant effect $(p<0.01)$ on LOI value. Compared with the untreated wood samples, the LOI values of the treated wood samples were significantly increased with the increased flame-retardant addition $(p<0.01)$. The LOI value of the untreated wood was minimized to $21.0 \%$, while it peaked at $46.3 \%$, counting a $54.64 \%$ increase $(p<0.01)$, with BL-flame-retardant

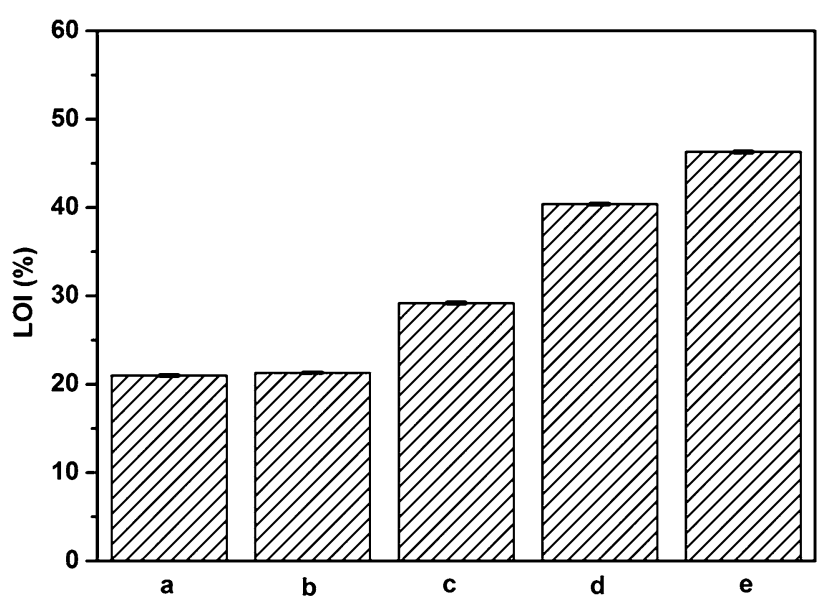

Fig. 4 LOI of poplar wood veneers treated with dye and flame retardant: a untreated wood, b dyed wood veneer with BL-flameretardant concentration of $0 \%$, $\mathbf{c}$ dyed wood veneer with BL-flameretardant concentration of $10 \%$, d dyed wood veneer with BLflame-retardant concentration of $20 \%$, and $\mathbf{e}$ dyed wood veneer with BL-flame-retardant concentration of $30 \%$

concentration of $30 \%$. This can likely be attributed to the increase in BL-flame-retardant molecules having increased the probability of BL-flame retardant penetrating the wood fiber. Moreover, more BL-flame-retardant molecules took precedence over the dye molecules and occupied cell cavities, the wood vessel, and the aperture [36]. Furthermore, 

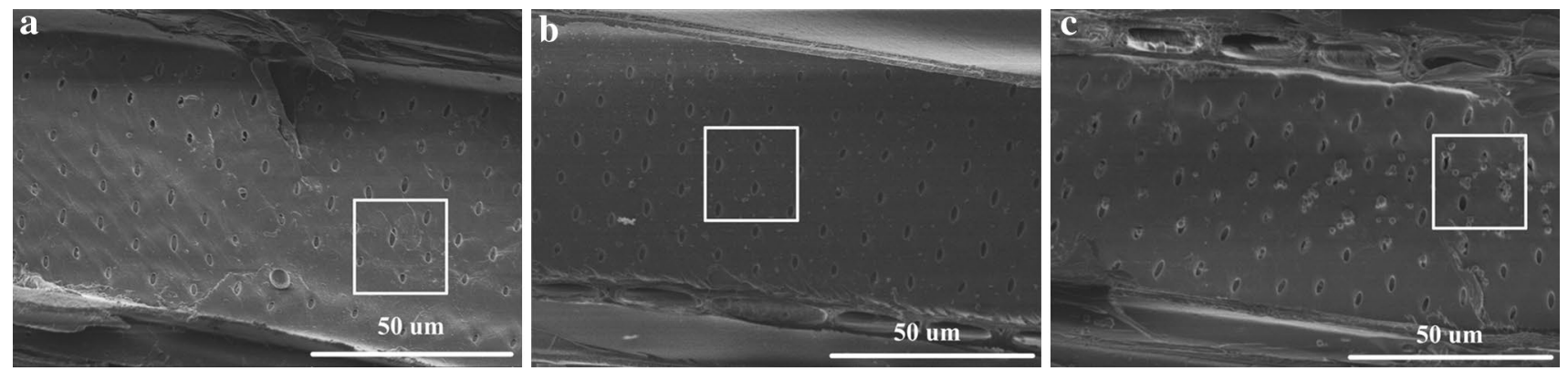

Fig. 5 SEM images: a untreated wood, b dyed wood, and $\mathbf{c}$ dyed and fire-retardant-treated wood

Table 4 SEM-EDX values of sulfur, nitrogen, and phosphorus (Fig. 5)

\begin{tabular}{llll}
\hline Area $(w t \%)$ & Sulfur & Nitrogen & Phosphorus \\
\hline$a$ & 1.28 & 0.00 & 1.32 \\
$b$ & 7.12 & 8.36 & 3.51 \\
$c$ & 3.69 & 8.05 & 6.97 \\
\hline
\end{tabular}

more oxygen was necessary to keep the samples burning at higher LOI values, indicating enhanced fire-retardant properties [40-42]. In short, the fire-retardant properties of wood samples simultaneously treated with acid red GR dye and BL-flame retardant was improved compared to untreated wood. Therefore, the treated wood could be safely used in furniture, decoration, and construction industries, etc.

\section{SEM and EDX analysis}

Figure 5 shows the morphologies of untreated wood, treated wood with acid red GR dye $(0.5 \%)$, and treated wood with acid red GR dye $(0.5 \%)$ and BL-flame retardant $(30 \%)$. The untreated wood clearly contained empty pits and smooth vessel walls (Fig. 5a). After dyeing, the empty pits were occupied by a number of dye molecules; dye molecules were also dispersed uniformly in the vessel walls (Fig. 5b). After the combination dyeing and flameretardancy treatment, the pits were filled with dye and BLflame-retardant molecules, while the wood vessel walls were rough. The dye and BL-flame-retardant molecules in the sample also clustered and adhered to the cell walls and pits (Fig. 5c).

As described above, we used SEM-EDX to determine the elemental composition of the untreated and treated wood samples. The results are shown in Table 4. From data labeled ' $b$ ', the $\mathrm{S}$ and $\mathrm{N}$ contents of treated samples notably increased compared to the untreated samples, suggesting that the molecules visible under SEM were, indeed, dye molecules. Comparing data between ' $c$ ' and ' $a$ ', the content level of $\mathrm{S}, \mathrm{N}$, and $\mathrm{P}$ all increases, which shows that the agglomerates were dye and flame-retardant molecules.

\section{Contact angle}

The contact angles of untreated and treated wood samples are shown in Table 5. The contact angles of the three test liquids were acquired via the linear regression method. The changes in contact angle for water on the wood surface were significant $(p<0.01)$ upon the addition of flame retardant. The contact angle ranged from $112.49^{\circ}$ to $65.18^{\circ}$, which was confirmed a significant decrease by statistical analysis $(p<0.01)$. With the increasing BL-flame-retardant concentration, the contact angle decreased. This is because the BL-flame retardant used in the study belongs to the nitrogen-phosphorus (N-P) flame-retardant type and has a high hygroscopicity [43]. Certain substances were extracted from the wood after treatment at high temperature and high humidity, as well, further enhancing the wettability of the treated wood surface [44]. The contact angle
Table 5 Contact angles of poplar wood veneers treated with dye and flame retardant (standard deviations in parentheses)

\begin{tabular}{llll}
\hline Sample & \multicolumn{1}{l}{$\theta\left(^{\circ}\right)$} & \\
\cline { 2 - 4 } & Water & Formamide & Diiodomethane \\
\hline Untreated wood & $112.49(4.05)$ & $94.74(6.15)$ & $36.21(3.26)$ \\
Dyed wood with BL-flame-retardant concentration of 0\% & $109.96(5.63)$ & $92.42(1.62)$ & $39.68(1.71)$ \\
Dyed wood with BL-flame-retardant concentration of 10\% & $70.38(2.93)$ & $59.35(2.99)$ & $31.21(1.97)$ \\
Dyed wood with BL-flame-retardant concentration of 20\% & $74.05(0.95)$ & $65.99(3.23)$ & $25.84(2.30)$ \\
Dyed wood with BL-flame-retardant concentration of 30\% & $65.18(4.50)$ & $59.88(4.05)$ & $22.91(1.81)$ \\
\hline
\end{tabular}


changes for formamide on the wood surface were similar to those of water, but slightly smaller. The reason is that formamide is a strong hydrogen bonding liquid which reduces the interfacial free energy at the liquid-solid interface through acid-base interactions [45]. There was a significant decrease of contact angle for diiodomethane on wood surface $(p<0.05)$ upon the addition of flame retardant. Moreover, the contact angle was much smaller than that of water due to the apolarity of the liquid and its low surface tension. As shown in Table 5, the standard deviations of the contact angles were small, so the calculation method was appropriate.

\section{Surface free energy}

The surface free energies of untreated and treated wood samples are shown in Fig. 6. The surface free energy of each wood sample simultaneously treated with dye and flame retardant was higher than that of untreated wood $\left(41.27 \mathrm{~mJ} \mathrm{~m}^{-2}\right)$. This improvement in surface free energy is beneficial in regard to veneer gluing. While the surface free energy of wood treated with dye $(b)$ was $39.58 \mathrm{~mJ} \mathrm{~m}^{-2}$, which was slightly lower than that of the untreated wood. This may be because the dye used in the study did not chemically react with the main components of the wood, and just filled the porosity of the wood [46]. The surface free energy of the treated wood increased as BL-flameretardant concentration increased, reaching its maximum $\left(46.65 \mathrm{~mJ} \mathrm{~m}^{-2}\right)$ at $30 \%$ BL-flame-retardant concentration. It is due to the fact that the chemical composition of the treated wood was altered by the reaction of BL-flame retardant with the lignin or hemicellulose of the wood [37,

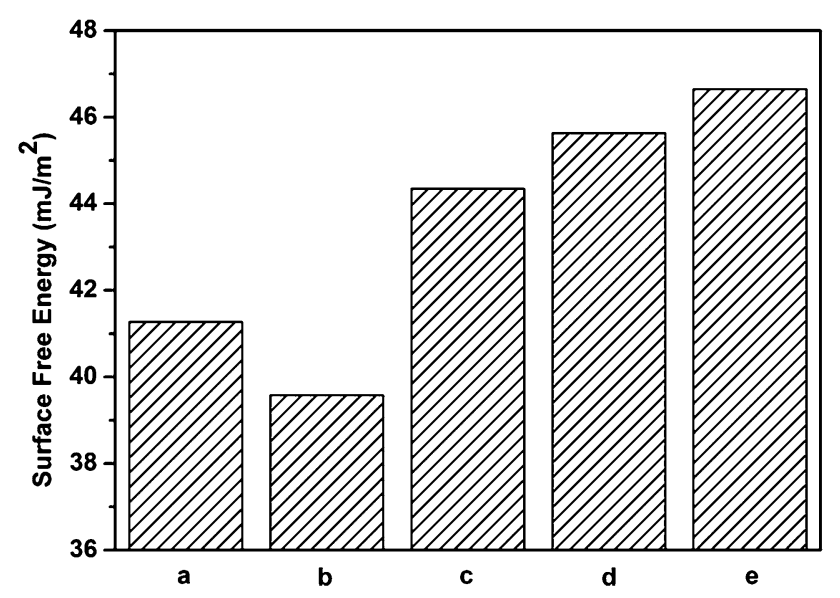

Fig. 6 Surface free energy of poplar wood veneers treated with dye and flame retardant: a untreated wood, $\mathbf{b}$ dyed wood veneer with BLflame-retardant concentration of $0 \%$, $\mathbf{c}$ dyed wood veneer with BLflame-retardant concentration of $10 \%$, $\mathbf{d}$ dyed wood veneer with BLflame-retardant concentration of $20 \%$, and e dyed wood veneer with BL-flame-retardant concentration of $30 \%$
47]. When the treated wood is used for wood-based composites (i.e., reconstituted decorative lumber processing), the surface adhesion and bond strength are better with the higher surface free energy [8].

\section{Dynamic wettability}

Figure 7 shows the model fit line of contact angle as a function of time for the untreated and treated wood samples. The contact angle quickly decreased during the initial $10 \mathrm{~s}$ of the wetting process, and then slowly stabilized and reached a relative equilibrium state [32]. The contact angle of the untreated wood decreased more rapidly at the beginning of the process than that of the dye-only wood as cracks in the wood surface were filled with dye molecules, reducing the surface roughness [48]. The dye particles also impeded the adhesive from spreading on the wood surface, forcing the contact angle on the surface of the dyed wood veneer above that on the untreated wood veneer [49]. Compared with the study of Qin et al., the contact angle changed at a higher rate as BL-flame-retardant concentration increased due to the retardant's high level of hygroscopicity [17]. According to the literatures, the wood surface can definitely present excellent wettability at a contact angle less than or equal to $30^{\circ}[15,19]$. In our study, after treatment, the contact angles were less than $15^{\circ}$ after $10 \mathrm{~s}$, which can generate a strong adhesive joint [14].

The initial and equilibrium contact angles of adhesive on the treated wood surface, $K$ values, asymptotic standard errors (SE), and the coefficients of determination $\left(R^{2}\right)$ calculated in Origin 8.0 via Marquardt-Levenberg algorithm are presented in Table 6 . The regression equation exhibited a high fitting degree. $R^{2}$ values exceeded $97 \%$ and SE were no more than $7 \%$ for the examined wood surfaces,

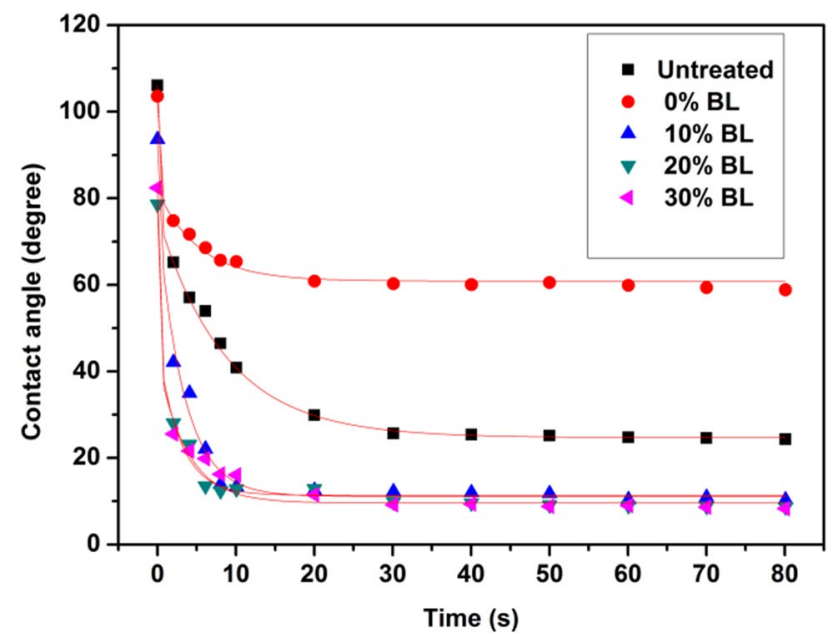

Fig. 7 Contact angle changes as a function of time for adhesive on different processed wood surface 
Table 6 Contact angles and $K$ values on different processed wood surface treated with dye and flame retardant

\begin{tabular}{|c|c|c|c|c|c|c|}
\hline \multirow[t]{2}{*}{ Sample } & \multicolumn{3}{|c|}{ Contact angle } & \multicolumn{3}{|c|}{$K$ value } \\
\hline & $\theta_{\mathrm{i}}\left(^{\circ}\right)$ & $\theta_{\mathrm{e}}\left(^{\circ}\right)$ & $\begin{array}{l}\text { Percent } \\
\text { decrease }(\%)\end{array}$ & $K$ & SE & $R^{2}$ \\
\hline Untreated wood & 106.06 & 24.32 & 77.07 & 0.237 & 0.046 & 0.996 \\
\hline Dyed wood with BL-flame-retardant concentration of $0 \%$ & 103.57 & 58.83 & 43.20 & 0.111 & 0.067 & 0.988 \\
\hline Dyed wood with BL-flame-retardant concentration of $10 \%$ & 93.61 & 10.34 & 88.95 & 0.323 & 0.025 & 0.987 \\
\hline Dyed wood with BL-flame-retardant concentration of $20 \%$ & 78.60 & 8.65 & 88.99 & 0.354 & 0.034 & 0.991 \\
\hline Dyed wood with BL-flame-retardant concentration of $30 \%$ & 82.41 & 8.32 & 89.90 & 0.370 & 0.029 & 0.971 \\
\hline
\end{tabular}

altogether suggesting that the wetting model used in this study accurately represents the adhesive wetting process on treated wood surfaces. For the treated wood samples, the decrease in contact angles and $K$ value peaked at $89.90 \%$ and 0.370 , respectively, at a BL-flame-retardant concentration of $30 \%$.

\section{Conclusions}

Our most notable conclusions can be summarized as follows.

Dye uptake can be improved by adding BL-flame retardant. As flame-retardant concentration increased, dye uptake initially increased and then slightly decreased. Drug load, color difference, and LOI values all increased as flameretardant concentration increased.

FTIR results indicated that the dye permeated wood without any chemical reaction, while the flame retardant did chemically react with the wood. SEM revealed that dye and flame-retardant molecules were diffused into the cell cavities, wood vessel, and aperture after treating the veneer with dye and flame retardant simultaneously.

The surface free energy of the combination-treated wood was higher than that of the untreated wood sample. The contact angle for adhesives on the wood surface decreased over time, and $K$ values increased as flame-retardant concentration increased, indicating better spreading and penetration ability of adhesive drops on treated wood surfaces.

Taken together, our results indicate that the proposed technique for simultaneously treating wood with dye and flame retardant is readily applicable to wood modification and wood processing.

Acknowledgements The work was financially supported by the Project for Follow-up Hot of Beijing Forestry University, 2016BLRD03 (No. 2016ZCQ01).

\section{Compliance with ethical standards}

Conflict of interest The authors declare that there is no conflict of interest regarding the publication of this paper.

\section{References}

1. Gindl M, Reiterer A, Sinn G, Stanzl-Tschegg SE (2004) Effects of surface on wettability, surface chemistry, and adhesion of wood. Holz Roh Werkst 62:273-280

2. Bryne LE, Wålinder MEP (2010) Ageing of modified wood. Part 1: wetting properties of acetylated, furfurylated, and thermally modified wood. Holzforschung 64:295-304

3. Xiong GB (2005) Study on dyeing, enhancement and dimensional stability of fast-growing poplar. Dissertation, Nanjing Forestry University, Nanjing

4. Jia $\mathrm{Z}$ (2012) The study of nano- $\mathrm{CaCO}_{3}$ /fast-growing poplar composite and preparing building templates. Dissertation, Northeast Forestry University, Harbin

5. Subyakto, Kajimoto T, Hata T, Ishihara S, Kawai Shuichi, Getto H (1998) Improving fire retardancy of fast growing wood by coating with fire retardant and surface densification. Fire Mater 22:207-212

6. Taghiyari HR (2012) Fire-retarding properties of nano-silver in solid woods. Wood Sci Technol 46:939-952

7. Pries M, Mai C (2013) Fire resistance of wood treated with a cationic silica sol. Eur J Wood Prod 71:237-244

8. Sang BP, Min L, Dong WS, Sang ML, Jong IK (2014) Fire performance of carbonized medium density fiberboard manufactured at different temperatures. J Wood Sci 60:74-79

9. Pan J, Mu J, Wu ZX, Zhang XT (2014) Effect of nitrogenphosphorus fire retardant blended with $\mathrm{Mg}(\mathrm{OH})_{2} / \mathrm{Al}(\mathrm{OH})_{3}$ and nano- $\mathrm{SiO}_{2}$ on fire-retardant behavior and hygroscopicity of poplar. Fire Mater 38:817-826

10. Baharoğlu M, Nemli G, Sarı B, Bardak S, Ayrılmıs N (2012) The influence of moisture content of raw material on the physical and mechanical properties, surface roughness, wettability, and formaldehyde emission of particleboard composite. Compos Part B 43:2448-2451

11. Gindl M, Reiterer A, Sinn G, Stanzl-Tschegg SE (2004) Effects of surface ageing on wettability, surface chemistry, and adhesion of wood. Holz Roh Werkst 62:273-280

12. Rathke J, Sinn G (2013) Evaluating the wettability of MUF resins and pMDI on two different OSB raw materials. Eur J Wood Prod 71:335-342

13. Wang S, Zhang Y, Xing C (2007) Effects of drying method on the surface wettability of wood strands. Holz Roh Werkst 65:437-442

14. Jennings JD, Zink-Sharp A, Kamke FA, Frazier CE (2005) Properties of compression densified wood. Part I: bond performance. J Adhes Sci Technol 19:1249-1261

15. Fang Q, Cui HW, Du GB (2016) Surface wettability, surface free energy, and surface adhension of microwave plasmatreated Pinus yunnaensis wood. Wood Sci Technol 50:285-296 
16. De Gennes, PG (1985) Wetting: statics and dynamics. Rev Mod Phys 57:827-863

17. Qin ZY, Gao Q, Zhang SF, Li JZ (2014) Surface free energy and dynamic wettability of differently machined poplar woods. BioResources 9:3088-3103

18. Qin TF, Yan HP (2001) A study on effect of esterification and graft copolymerization process on surface free energy of wood. Scientia Silvae Sinicae 37:97-100

19. Qin ZY, Chen H, Gao Q, Zhang SF, Li JZ (2015) Wettability of sanded and aged fast-growing poplar wood surfaces: I. surface free energy. BioResources 10:1008-1023

20. Zhang DR (2005) Study on producing technology of dyeing and fire-retardant glue-lumber. Dissertation. Beijing Forestry University, Beijing

21. Li WZ (2011) The preparation technology of flame retardant plywood with decorative and environmental concern. Dissertation. Beijing Forestry University, Beijing

22. Tang R, Yu Z, Luna M, Zhang Y, Qi C (2015) Mechanisms and properties of chitosan-assisted bamboo dyeing. BioResources 10:3326-3336

23. Zhang X, Mu J, Chu D, Zhao Y (2016) Synthesis of fire retardants based on $\mathrm{N}$ and $\mathrm{P}$ and poly (sodium silicate-aluminum dihydrogen phosphate) (PSADP) and testing the flame retardant properties of PSADP impregnated poplar wood. Holzforschung 70:341-350

24. Romagnoli M, Segoloni E, Luna M, Margaritelli A, Gatti M, Santamaria U, Vinciguerra V (2013) Wood color in Lapacho (Tabebuia serratifolia): chemical composition and industrial implications. Wood Sci Technol 47:701-716

25. EN ISO 4589-2 (1996) Plastics-determination of burning behaviour by oxygen index-part 2, ambient temperatures. International Organization for Standardization, Geneva

26. van Oss CJ, Good RJ, Chaudhury MK (1988) Additive and nonadditive surface tension components and the interpretation of contact angle. Langmuir 4:884-891

27. van Oss CJ, Giese RF, Good RJ (1990) Reevaluation of the surface tension components and parameters of polyacetylene from contact angle of liquids. Langmuir 6:1711-1713

28. Liptakova E, Kudela J (1994) Analysis of the wood-wettinh process. Holzforschung 48:139-144

29. Tang L, Zhang R, Zhou X, Pan M, Chen M, Yang X, Zhou P, Chen Z (2012) Dynamic adhesive wettability of poplar veneer with cold oxygen plasma treatment. BioResources 7:3327-3339

30. Topala I, Dumitrascu N (2007) Dynamics of the wetting process on dielectric barrier discharge (DBD)-treated wood surfaces. J Adhes Sci Technol 21:1089-1096

31. Xu HN, Shen QY, Ouyang XK, Yang LY (2010) Wetting of soy protein adhesives modified by urea on wood surfaces. Eur $\mathrm{J}$ Wood Prod 70:11-16

32. Shi SQ, Gardner DJ (2001) Dynamic adhesive wettability of wood. J Wood Fiber Sci 33:58-68
33. Kang H, Wang Z, Zhang W, Li J, Zhang S (2016) Phys icochemical properties improvement of soy protein isolate films through caffeic acid incorporation and tri-functional aziridine hybridization. Food Hydrocolloids 61:923-932

34. Chu D, Mu J, Zhang L, Li Y (2016) Promotion effect of NP fire retardant pre-treatment on heat-treated poplar wood. Part 2: hygroscopicity, leaching resistance, and thermal stability. Holzforschung. doi:10.1515/hf-2016-0213

35. Wang PQ, Tai DS, Liao JY, Li MD (1987) Wood chemistry. China Forestry Publishing House, Beijing

36. Wang X, Zhang Y, Yu Z, Qi C (2016) Properties of fast-growing poplar wood simultaneously treated with dye and flame retardant. Eur J Wood Prod. doi:10.1007/s00107-016-1142-y

37. Li WZ, Yu ZM, Chen LY, Jiang XD (2010) Study on the discoloration laws of poplar veneer treated by BL-flame retardant. J Anhui Agri Sci 38:12057-12059

38. Wang X, Yu Z, Zhang Y, Wang F (2016) Dyeing and flame retardant properties of poplar veneer. J Northwest For Univ 31:276-280

39. Wang YL (2006) Application study of BL-environmental concerned fire-retardant in particleboard. Dissertation. Beijing Forestry University, Beijing

40. Zhang L (2007) The application study of BL-environmental friendly fire retardant on textile. Dissertation. Beijing Forestry University, Beijing

41. Arora S, Kumar M, Kumar M (2012) Catalytic effect of bases in impregnation of guanidine nitrate on Poplar (Populus) wood:flammability and multiple heating rate kinetic study. J Therm Anal Calorim 107:1277-1286

42. Kumar M, Kumar M, Arora S (2013) Thermal degradation and flammability studies of wood coated with fly ash intumescent composites. J Indian Acad Wood Sci 10:125-133

43. Chen LY (2010) The preparation technology of flame-retarded plywood treated with BL flame retardant. Dissertation. Beijing Forestry University, Beijing

44. Jiang ZH, Yu WJ, Yu YL (2005) A study on wettability of bamboo wood surface. J Bamboo Res 24:31-38

45. Stehr M, Gardner DJ, Wålinder MEP (2001) Dynamic wettability of different machined wood surface. J Adhes 76:185-200

46. Li H, Yu ZM (2005) Combinative mechanism between dyestuff and wood. J Beijing For Univ 27:78-81

47. Wang XQ, Yu ZM, Zhang Y (2016) Effect of pretreatment on dyeing and fire-retarding properties of poplar veneers. J Fujian Agric For Univ 45:1-5

48. Baldan A (2012) Adhesion phenomena in bonded joints. Int $\mathbf{J}$ Adhes Adhes 38:95-116

49. Wei SY, Shi JY, Gu JY, Wang D, Zhang YH (2016) Dynamic wettability of wood surface modified by acidic dyestuff and fixing agent. J Appl Surf Sci 258:1995-1999 